University of South Carolina

Scholar Commons

$12-2000$

\title{
Functional Projections of Predicates: Experimental Evidence from Coordinate Structure Processing
}

Stanley William Dubinsky

University of South Carolina - Columbia, dubinsky@sc.edu

Marie Egan

The College of New Jersey

A. Rene Schumauder

Matthew J. Traxler

University of South Carolina - Columbia

Follow this and additional works at: https://scholarcommons.sc.edu/ling_facpub

Part of the Linguistics Commons

\section{Publication Info}

Postprint version. Published in Syntax, Volume 3, Issue 3, 2000, pages 182-214.

Dubinsky, S., Egan, M., Schmauder, A. R., \& Traxler, M, J. (2000). Functional projections of predicates:

Experimental evidence from coordinate structure processing. Syntax, 3(3), 182-214.

DOI: 10.1111/1467-9612.00032_1

(c) Syntax, 2000, Blackwell Publishing

The definitive version is available at: www.blackwell-synergy.com

This Article is brought to you by the Linguistics, Program of at Scholar Commons. It has been accepted for inclusion in Faculty Publications by an authorized administrator of Scholar Commons. For more information, please contact digres@mailbox.sc.edu. 


\title{
Functional projections of predicates:
}

\section{Experimental evidence from coordinate structure processing ${ }^{1}$}

\author{
Stanley Dubinsky , Marie Egan ${ }^{H}$, A. René Schmauder, and Matthew J. Traxler \\ *University of South Carolina, ${ }^{H}$ The College of New Jersey,
}

\author{
Address: $\quad$ Linguistics Program \\ University of South Carolina \\ Columbia, SC 29208 \\ e-mail: $\quad$ dubinsky@sc.edu \\ megan5@home.com \\ jethawk@worldnet.att.com \\ traxlerm@gwm.sc.edu \\ telephone: $\quad 803-777-2063$ \\ fax: $\quad$ 803-777-9064
}




\title{
Functional projections of predicates: \\ Empirical evidence from coordinate structure processing
}

\begin{abstract}
This paper reports the results of six experiments involving an on-line self-paced reading task that examine the processing of coordinate small clause predicate phrases versus coordinated arguments NPs. The results have particular significance for the analysis of small clause complement constructions, and support accounts wherein the small clause complement has an Agr projection associated with it. An adequate explanation of the processing of small clause coordination is shown to motivate a new parsing principle, Coordination Feature-matching, which accounts for the longer reading times observed for the coordination of predicates in small clause complements.
\end{abstract}

Key words: $\quad$ sentence processing, parsing principles, coordination, small clause, functional projections, grammatical agreement. 


\section{INTRODUCTION}

This paper reports six experiments on processing of coordinate constructions. The results support an independently motivated principle of the grammar, $\varphi$-feature checking, and illustrate that this principle is applied in a psychologically real way to the processing of sentences.

The present experiments focused on processing of coordinated SMALL CLAUSE (SC) predicate phrases and of coordinated argument NPs. The results indicate that the coordination of SC predicate phrases required significant additional processing resources as compared with the coordination of NP arguments. These results are not predicted by existing parsing principles such as minimal attachment, late closure, and integration cost (Frazier 1978, Gibson 1998). We take this fact, together with the evidence for the complexity of processing of predicate phrases, as motivation for another parsing principle. In particular, we claim that the introduction of a coordinated bare SC predicate phrase into a parse requires the parser to seek and identify the correct argument of that predicate. Further, processing difficulty associated with coordinate SC predicates only arises when the relation between the argument and the coordinated predicates is $\underline{\text { not }}$ mediated through a lexically overt functional head. Accordingly, we claim that the processing of bare SC predicate phrases involves covert functional projections which mediate, via $\varphi$-feature checking, the syntactic relations between the predicate and its associated argument.

This paper is organized as follows. Section 2 reviews the status of the SC construction in syntactic theory and, based on recent proposals in the literature, proposes coordinate-feature matching as a parsing principle which can explain the difficulty of processing coordinated SC predicates. Section 3 reports the results of the first three experiments, and demonstrates that our proposed parsing principle is indeed necessary. Section 4 presents the results of three additional experiments, designed to contrast the results obtained in Experiments 1-3 (involving bare SC 
predicates) with the processing of coordinated predicates whose functional structure is carried by overt auxiliary verbs. Section 5 argues for the appropriateness of the proposed Coordination Feature-matching Constraint, and considers the ramifications that our experimental results have for theories of small clause structure, arguing in favor of an AgrP analysis of SC structure over Williams $=(1983)$ Predication Theory and Stowell=s (1981) SC-constituent analysis.

\section{SMALl ClaUSES AS A SOURCE OF PROCESSING AMBIGUITY}

Researchers investigating human sentence processing have focused on sentence constructions that contain temporary ambiguities that are resolved during the course of sentence processing. Two constructions that have received significant attention are the main verb/reduced relative clause ambiguity as in (1), and the direct object/sentential complement ambiguity as in (2).

(1) The doctor sent the package was happy.

(2) The doctor found the package had broken.

Each of these two sentences involves an initial mistaken interpretation, (the doctor sent the package ... and the doctor found the package ...) which is resolved and corrected when a subsequent predicate is encountered (... was happy and ... had broken). A reader of sentence (1), upon encountering the predicate was happy, creates an analysis in which sent the package is a relative clause modifying the doctor, rather than the major predicate of the clause. Upon encountering the predicate had broken in (2), an analysis must be created such that the object of the main verb found is not the NP the package, but is instead the clause the package had broken.

The sentences in (1) and (2) can be compared with the another type of ambiguous sentence construction, shown in (3).

(3) Juanita considered the proposal on the table. 
Example (3) can be interpreted in two ways. Paraphrasing these two meanings, either $>$ Juanita considered the proposal which was on the table $=$ or $>$ Juanita considered the proposal to be on the table $={ }^{2}$ In the first interpretation, the proposal on the table is interpreted as a noun phrase (NP) the proposal, with a prepositional phrase modifier on the table. In the second interpretation, the proposal on the table is interpreted as a clause, and has a meaning which suggests an implicit, existential verb complex, to be. The fact that a clause-like interpretation of (3) does not depend upon an overt verb complex is what makes this construction different from sentences such as (2).

Because the two interpretations of (3) reflect the possible interpretations of the proposal and on the table (when they both follow a verb like consider), the ambiguity in Juanita considered the proposal ... is not resolved by the following phrase on the table. The ambiguity of sentences such as (3) can only be resolved through context, or through a disambiguating continuation, such as in (4).

(4) a. Juanita considered the proposal on the table, but Max did not yet want to discuss it.

b. Juanita considered the proposal on the table, while Max perused the one on the desk. In (4a), the additional clause forces the proposal on the table to be interpreted as $>$ the proposal to be on the table $=$, while in $(4 \mathrm{~b})$, the continuation forces a reading in which the proposal on the table is understood as $>$ the proposal which was on the table $=$.

Linguists refer to the clausal interpretation of constituents like the proposal on the table in (3) as SMALL CLAUSES (SCs). SCs are so labelled because they lack the inflectional morphology typically associated with sentential complement clauses, and because they can never stand alone as independent clauses. Consider the sentences in (5). 

a. We believed John ill.
b. We believed John to be ill.
c. We believed that John is ill.

The verb believe in (5b) and (5c) is followed by an infinitival clause in the first instance and by a tensed clause in the second. In example (5a), on the other hand, the complement of believe lacks the inflectional morphology associated with the other two sentences, consisting just of the NP

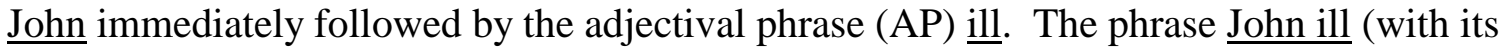

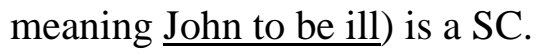

SC constructions can be of any type, where type refers to the grammatical category of the SC predicate. In (3), the predicative phrase in the SC is the prepositional phrase (PP) on the

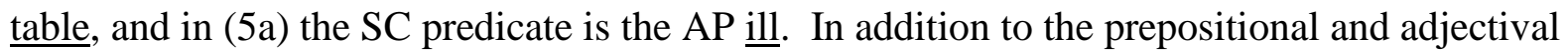
SCs depicted above in (3) and (5a), SCs can also be nominal or verbal as shown in (6).
a. Juanita considered Joe a good friend.
(Nominal)
b. Juanita saw Susan cross the street.
(Verbal)

In (6a), the SC is Joe a good friend and the SC predicate is the NP a good friend. In (6b), the SC is Susan cross the street (n.b. this phrase is judged a SC because the verb lacks the inflectional ending -es and cannot stand alone as a sentence) and the SC predicate is the uninflected verb phrase (VP) cross the street.

Traditionally, and until recently, there have been two prevailing views of small clause structure. On one side are syntacticians, beginning with Stowell (1981), who adopt a CONSTITUENT (or BINARY) ANALYSIS of small clauses.

(7) John wanted the cookies baked. 
According to Stowell=s 1981 analaysis (see also Bowers 1993, Rizzi 1986, and Starke 1995), the VP in (7) has a structure in which the NP the cookies and the AP baked form a syntactic constituent as in (8). The constituent view of SC structure treats the SC as an inflection-less sentence, and attributes to it an analogous structure. Under this analysis, the NP the cookies is interpreted as the subject of the SC predicate baked as a consequence of its occupying a subjectlike position in the PS-tree.

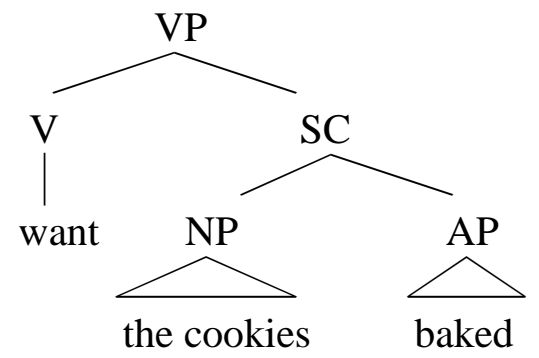

Williams (1983a) first advanced a PREDICATION (or TERNARY) ANALYSIS of SC structure. Williams 1983a (see also Carrier \& Randall 1992) proposes a ternary branching VP structure for (7), as shown in (9).

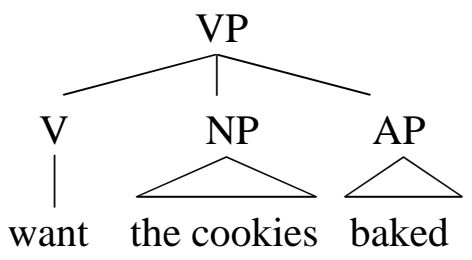

Under this view, syntactic (or constituent) structure has little to do with SC interpretation.

Instead, a property-denoting phrase (such as a PP or AP) can PREDICATE (i.e. assign a property to) an NP by being in the same clause with it. PREDICATION (see Williams 1980) is distinguished from modification, in which a PP or AP $\underline{\underline{\text { restricts }}}$ the reference of the NP.

In the past several years, the constituent (or binary) analysis of SC constructions has evolved into one in which a functional projection is claimed to mediate between the SC subject 
and the SC predicate. This view of predicate coordination comes out of proposals by Raposo and Uriagereka (1990), Cardinaletti and Guasti (1992) and Legendre (1996), among others. Based on ideas put forth by Horn and Lightfoot (1987) and Chomsky (1989), these researchers propose that SC predicates (AP predicates in particular) have grammatical agreement properties (AGREEMENT PROJECTIONS in their terms). Thus, the AP predicate in a SC construction must bear the same $\varphi$ features (person, number, and gender) as its NP subject. This is particularly salient in Romance languages, such as French and Italian, in which NPs are richly endowed with gender features in addition to person and number, and adjectives are inflected for these features. If we were to apply this analysis to the VP in (7), its structure would be represented as in (10).

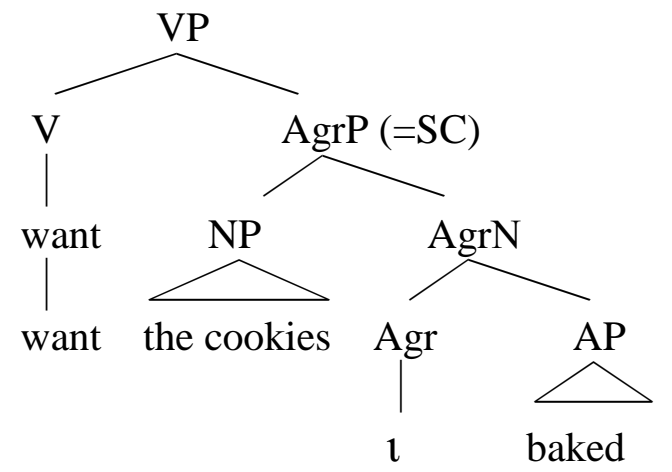

In (10), the $\varphi$-features of the NP the cookies are checked against those of its AP predicate in the specifier position of AgrP. ${ }^{3}$

While English agreement morphology is not as complex as that of Romance languages, agreement effects are visible in some English SC constructions. For example, in (11) the NP predicate of a SC must agree in number with its subject.
a. John considers them [PLURAL] $_{\text {good lawyers }}^{\left[\text {PLURAL }_{]} / * \text { a good lawyer }\right.}$ lSINGULAR]
b. John considers him [SINGULAR] $*_{\text {good lawyers }}$ [PLURAL] $_{\text {a }} /$ good lawyer [SINGULAR]

In (11a), the noun in the predicate NP must be plural to match the number feature of the SC 
subject them. This requirement is readily explained by assuming, following Raposo and Uriagereka (1990) and Cardinaletti and Guasti (1992), that the agreement relation between the subject NP them and the head noun of the predicate NP lawyers is mediated through AgrP. In (12), we have represented the relevant features with the variables $\Phi$ and X.

$$
\begin{aligned}
& \text { a. John considers } \left.\left[{ }_{\mathrm{AgrP}}\left[{ }_{\mathrm{NP}} \text { them }\right]_{\Phi} \operatorname{Agr}\left[\mathrm{AgrN}_{\mathrm{NPP}} \operatorname{good} \text { lawyers }_{\Phi}\right]\right]\right] \quad \Phi=\mathrm{X} \\
& \text { b. } \left.\left.{ }^{*} \text { John considers }\left[\text { AgrP }[\mathrm{NP} \text { them }]_{\Phi} \text { Agr [AgrN [NP a good lawyer } \mathrm{X}\right]\right]\right] \quad \Phi \square \mathrm{X}
\end{aligned}
$$

If the subject NP and the head noun of the predicate NP match, as in (12a), the structure is good. If they do not, as in (12b), then the structure is ungrammatical.

Now, suppose that feature matching is entailed between the subject of a SC and its predicate irrespective of whether or not there is overt morphological indication of such matching. That is, suppose that predicates have to be able to agree with their subjects and that this involves abstract agreement, part of Universal Grammar. This extra syntactic structure, in the form of an Agr projection, might be expected to use processing resources that are not required when a SC structure is not posited. For instance, we might expect the NP-PP sequence in (13a), in its SC interpretation, to be harder to process than the NP-PP sequence in (13b).
a. I want the boys on the bus immediately.

b. I parked the car on the street this morning.

This is presumably because (13a) involves the extra AgrP structure shown in (14a), while the VP of (13b) is simpler, as shown in (14b).

a. [vP want [AgrP [NP the boys] Agr [AgrN [PP on the bus]]] ... ]

b. [vp parked [NP the car] [PP on the street] ... ] 
If this view of SC structure is correct, then the coordination of SC predicate phrases might utilize more processing resources than the coordination of arguments or modifiers, which do not require feature matching. To illustrate, we would predict that the second PP in (15a), being a SC predicate, should cause more processing difficulty than the second NP in (15b).

(15) a. The coach wants the boys [PP on the bus], not [PP in front of it]

b. The coach wants [NP the boys on the bus], not [NP the ones in the van]

According to our account, agreement features of the SC subject in (15a) must be checked against features of the conjunct to make sure that they match. This requires resources for $\varphi$-feature matching which are not required of the second conjunct in (15b). We formalize this process in the Coordination Feature-matching Principle.

(16) Coordination Feature-matching: The coordination of constituents which must agree in $\varphi$ features with a subject causes processing difficulty in comparison to coordination of constituents for which $\varphi$-feature checking is irrelevant.

$\varphi$-feature checking plays a role in SC predicate coordination, but not in argument coordination. Consider the SC structures illustrated in (17). ${ }^{4}$

a. John considers $\left[\mathrm{AgrP} \varphi[\mathrm{NP} \text { them }]_{\mathrm{Agr} \Phi}[\mathrm{NP}\right.$ good lawyers $\left.]\right] \ldots$ and [AgrPX AgrX $_{\mathrm{NP}}$ very nice people $\left.]\right] \quad \operatorname{Agr} \Phi=\mathrm{AgrX}$ b. ${ }^{*}$ John considers $\left[\mathrm{AgrP} \varphi[\mathrm{NP} \text { them] }]_{\mathrm{Agr} \Phi}[\mathrm{NP}\right.$ good lawyers $\left.]\right] \ldots$

$$
\text { and [AgrPX AgrX [NP a very nice person]] } \quad \operatorname{Agr} \Phi \square \text { AgrX }
$$

To successfully coordinate the predicate NP good lawyers with the predicate NP very nice people, the processor must check to make certain that the features of the two predicates match, and further that they match the subject NP them. That is, in (17), the content of AgrФ must be 
identical to that of AgrX. In contrast, coordination of NP complements involves no such complications: singular and plural NP complements can be conjoined, as shown in (18).

(18) John met at the party [NP a good lawyer] and [NP some very nice people]

In (18), the two object complement NPs do not agree in number, but this does not impede coordination. The next section presents the results of three experiments that were designed to compare the processing of coordinate SC predicates with that of coordinate complements.

\section{EXPERIMENTS 1-3}

Experiments 1-3 compared the processing of coordinated SC predicates as shown in (15a), above, with the coordination of complements, as shown in $(15 \mathrm{~b})$. The materials were ambiguous in the first clause, as is the first clause of (15a) and (15b): The coach wants the boys on the bus. The phrase the boys on the bus can be interpreted either as a SC or as an NP complement. The second clause in each experimental sentence was manipulated to create either a SC complement interpretation, e.g. not in front of it, or an NP complement interpretation, e.g. not the ones in the

van. In Experiments 1-3, the category of post-nominal material was distinct. In Experiment 1, the first clause of each experimental sentence ended with an adjectival participle as in (19).

a. Mary wanted the cake displayed, not sitting on the cutting board on the table. $\quad$ (SC complement condition)

b. Mary wanted the cake displayed, not the one sitting on the cutting board on the table. (NP complement condition)

In Experiment 2, the ambiguous clause of each experimental sentence ended with a PP, as seen in (15), and as in (20). 
a. Mary wanted the cake in the window, not sitting on the cutting board on the table. (SC complement condition)

b. Mary wanted the cake in the window, not the one sitting on the cutting board on the table. (NP complement condition)

In Experiment 3, the ambiguous clause ended with an adjectival participle plus a PP, as in (21).

a. Mary wanted the cake displayed in the window, not sitting on the cutting board on the table. $\quad$ (SC complement condition)

b. Mary wanted the cake displayed in the window, not the one sitting on the cutting board on the table. (NP complement condition) We tested three ambiguous clause types to make certain that construction-specific biases did determine the results. The ambiguous region of the Experiment 1 materials, like example (19), tends to receive a SC complement interpretation, while that of the Experiment 2 materials, like example (20), tends to be interpreted as an NP complement. In Experiment 3, this region, as in example (21), is not strongly biased either way. If the Coordination Feature-matching principle is correct, then we would predict longer reading times in the disambiguating regions under the SC complement condition for all three experiments. If it is not, then we would predict: (i) no reliable differences in reading time in the disambiguating region in either condition; or (ii) reliably longer reading times in the disambiguating region for NP complements.

\section{INTERPRETIVE BIAS NORMING}

Prior to collecting reading times for our experimental sentences, we assessed what preference, if any, readers had for interpreting the temporarily ambiguous material from the first clause. Using a reading procedure identical to the experimental reading procedure (see below), each norming participant read the first line of the Experiment 1 sentences (like 19), Experiment 2 sentences 
(like 20), or Experiment 3 sentences (like 21), interspersed among 48 filler sentences. Each line ended in a period to form a complete sentence (e.g., subjects read Mary wanted the cake

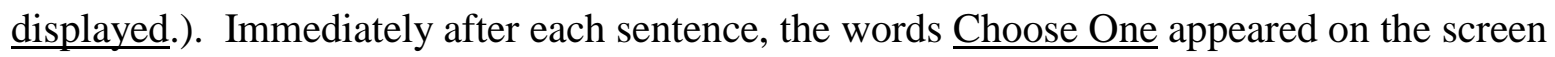
above two paraphrases of the previous sentence. A participant who read Mary wanted the cake displayed. in moving window format then saw Choose one: A. Mary wanted the cake to be put on display. B. Mary wanted the cake which was on display. Participants used response buttons to choose the best paraphrase. Paraphrase order was counterbalanced so that participants could not predict order of paraphrase types. The first line of the sentences tested in Experiment 1 was more likely to be interpreted as an SC- than an NP- complement [two-tailed $\underline{t}_{1}(29)=2.51, \underline{p}<$ $\left..02 ; \underline{\mathrm{t}}_{2}(23)=1.25, \underline{\mathrm{p}}>.2\right]$. Experiment 2 materials produced the opposite bias [two-tailed $\underline{\mathrm{t}}_{1}(29)$ $\left.=8.53, \underline{\mathrm{p}}<.001 ; \underline{\mathrm{t}}_{2}(23)=1.83, \underline{\mathrm{p}}=.08\right]$. Experiment 3 materials had no strong bias in either direction $\left[\underline{t}_{1}(29)=1.68, \underline{p}>.1 ; \underline{t}_{2}(23)=0.93, \underline{p}>.3\right]$.

\section{EXPERIMENT 1}

In Experiment 1, we explored the hypothesis that the $\varphi$-feature checking process would cause processing difficulty in SC constructions, relative to controls.

\section{METHOD}

Participants. Forty-eight native speakers of American English recruited from the University of South Carolina $=$ s Department of Psychology Human Participant Pool participated in Experiment 1 to fulfill part of their course requirements.

Materials. Materials resembled those shown above in (19) and had the same line breaks. The first clause contained a small clause complement with an adjectival predicate. The second, coordinate, clause began with the contrastive conjunction not, followed either by a gerundive or 
participial conjunct as in (19a)Cthe SC complement conditionCor by an NP conjunct as in (19b)Cthe NP complement condition. Note that the first clause was weakly ambiguous. That is, it had a dominant SC complement reading with a weaker NP complement reading. However, such phrases can indeed have NP interpretations. The phrases the guy seated, the cake displayed, and the girl sleeping are all acceptable subject NPs as shown in (22).

(22) a. The guy seated is the one you ought to ask, not the one standing.

b. The cake displayed looked better than the one in the freezer.

c. The girl sleeping, who appeared to be homeless, shivered each time the door opened. Twenty-four pairs of experimental sentences were constructed based on the model shown in (19). Line breaks always occurred at a comma and never in the middle of a critical region.

Thirty-six filler sentences were randomly intermixed with one sentence from each of the 24 sentence sets. A Latin-square design was used to counterbalance items across participants so that each version of each item appeared equally often and so that each participant saw only one version of each item. One third of the filler items were followed by a comprehension question, and responses were collected to ensure that participants attended to the stimuli.

Procedure. A self-paced, moving-window-display, word-by-word reading task (Just, Carpenter, \& Wooley 1982) was used to obtain single word reading times for the experimental sentences. These sentences were displayed on a Gateway computer which controlled the experiment and data collection. On each trial, a sentence appeared first represented as a series of underlines marking each letter position, with space information between words left intact (see Table 1). Subjects pressed a button on a button box, at their own pace, to reveal each word of the sentence. In this manner, sentences were displayed one word at a time, with each button press 
resulting in display of the next word in place of the underlines at that word position, and underlines replacing the previous word. Reading time per word in msec, measured as button press intervals, was the dependent measure.

Some additional analyses were based on deviation scores. Deviation scores were calculated by computing a regression equation for each subject individually. Length was entered as the independent variable, and reading time was entered as the dependent variable. That is, we used the length of each word to predict the subject $=\mathrm{s}$ reading time for that word. The residuals from this analysis reflect that part of the subject=s reading time that is unrelated to the length of the words that the subjects read. The deviation scores were calculated by subtracting the predicted reading time (based on the regression analyses) from the actual observed reading times. Higher deviation scores indicate greater difficulty processing a region.

$$
\text { C C C C C C C C }
$$

Tables 1, 2, and 3 about here

$$
\text { C C C C C C C }
$$

\section{RESULTS AND DISCUSSION}

Mean reading times for the regions of interest are reported in Table 2. Statistical analyses for the reading times from Experiment 1 are presented in Table 3. We report additional analyses contrasting the difficulty of the disambiguating participle in the SC complement condition (e.g.,

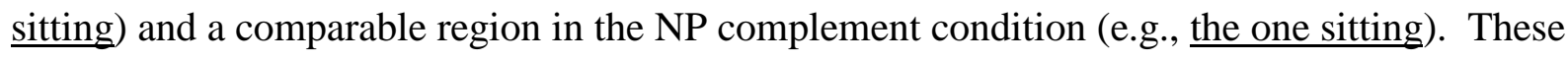
analyses provide additional evidence regarding the difficulty of processing information that disambiguates the sentences to SC- or NP-complement interpretations.

The first set of analyses showed that reading times were longer in the disambiguating region in the SC complement condition than in the NP complement condition. The results also 
indicated that the process of matching features in a coordinate construction had a measurable processing cost. Reading times were longer in the SC complement condition than in the NP complement condition at the verb (e.g., sitting) and at the following preposition (e.g., on); see Table 3. Also, reading times were longer in the SC complement condition than in the NP complement condition when the entire prepositional phrase was considered (e.g., on the cutting board).

Deviation score analyses (based on data from the region sitting in the SC complement condition and the one sitting in the NP complement condition) produced compatible results, as deviation scores were lower in the NP complement condition $(-20 \mathrm{~ms})$ than the SC complement condition $[-48 \mathrm{~ms} ; \mathrm{F} 1(1,47)=8.67, \underline{\mathrm{p}}<.01, \mathrm{MSe}=2221 ; \mathrm{F} 2(1,23)=10.4, \underline{\mathrm{p}}<.01, \mathrm{MSe}=$ 921].

Note that although the first clause of the experimental sentence is ambiguous, the noun + participle structure in Experiment 1 was biased in favor of an SC interpretation. If bias played any role at all, then we would have expected reading times for the NP complement condition to be longer because of reanalysis. Thus, interpretive bias cannot account for the pattern of results observed in this experiment.

\section{EXPERIMENT 2}

\section{METHOD}

Participants. Thirty-four participants from the same population as Experiment 1 participated in the self-paced reading portion of Experiment 2.

Materials. Twenty-four pairs of experimental sentences were constructed based on the model shown in (20).

Procedure. The experimental procedure was identical to Experiment 1. 


\section{RESULTS AND DISCUSSION}

Table 4 presents mean reading times by region and condition for Experiment 2. Table 5 presents the results of the statistical analyses. As in Experiment 1, Experiment 2 produced longer reading times in the SC condition throughout the disambiguating coordinate phrase. This pattern was present on the verb (e.g., sitting) and on each of the words in the two following prepositional phrases. In the first PP, reading times were longer in the SC condition at the word on, the, cutting, and board. In the final prepositional phrase, reading times were longer in the SC condition than in the NP-complement condition at on, the, and table (see Table 5).

Deviation score analyses produced compatible results, as deviation scores for the disambiguating regions were lower in the NP-complement condition (!164 ms) than the SC complement condition [!25 ms; F1 $(1,33)=69.63 \underline{p}<.0001, \mathrm{MSe}=4759 ; \mathrm{F} 2(1,23)=160.88, \underline{\mathrm{p}}<$ $.0001, \mathrm{MSe}=1503]$.

You will notice that there is an effect of condition in the region the cake, prior to the disambiguating region. This difference must be artifactual, as there were no differences in the stimuli between conditions at this point.

Together with the results of Experiment 1, the results of Experiment 2 are consistent with an account of sentence interpretation in which feature-matching plays a role in determining reading times regardless of bias. Note, though, that the ambiguous region of Experiment 2 exhibited a bias in favor of an NP-complement interpretation (in contrast with the comparable region in Experiment 1) and that reanalysis in the SC condition may also have contributed to the longer reading times. To address this concern, we performed Experiment 3, with materials that did not have a bias towards either the NP complement or the SC complement interpretation. 
C C C C C C C

Table 4 and 5 about here

C C C C C C C C

\section{EXPERIMENT 3}

In Experiment 3, the ambiguous region was not biased in favor of either a SC or an NP complement interpretation (see pre-test above). If the results obtained in Experiments 1 and 2 reflected the operation of the Coordination Feature-matching process and were not due to inherent biases in the materials, then in Experiment 3 we should also observe longer reading times in the regions of interest in the SC complement condition than in the NP complement condition.

\section{METHOD}

Participants. Forty-eight participants from the same population as the previous experiments participated in the self-paced reading portion of Experiment 3.

Materials. Twenty-four pairs of experimental sentences were constructed based on the model shown in (21). In all cases, the first clause contained a small clause complement with an adjective + PP predicate. The second, coordinate, clause began with the contrastive conjunction not, followed either by a gerundive or participial conjunct as in (21a)Cthe SC complement conditionCor by an NP conjunct as in (21b)Cthe NP complement condition.

Procedure. The procedure was identical to the previous experiments.

\section{RESULTS AND DISCUSSION}

Table 6 presents mean reading time by region and condition for Experiment 3. Table 7 presents the results of the statistical analyses. In Experiment 3, reading times were longer for the SC complement condition, ... the cake displayed in the window, not sitting on the cutting board 
..., than for the NP complement condition, ... cake displayed in the window, not the one sitting on the cutting board ... Thus, the results of Experiment 3 were fully consistent with those of Experiments 1 and 2. The longer reading times appeared at the preposition (e.g. on, at the following determiner (e.g., the), and across the entire prepositional phrase (e.g., on the cutting board)

As in the previous experiments, analyses were performed on deviation score data. These analyses also showed that the SC condition $(-35 \mathrm{~ms})$ produced greater disruption of processing following disambiguation than the NP-complement condition $[-50 \mathrm{~ms} ; \mathrm{F} 1(1,47)=4.67, \underline{\mathrm{p}}<.05$, $\mathrm{MSe}=1175 ; \mathrm{F} 2(1,23)=5.96, \underline{\mathrm{p}}<.05, \mathrm{MSe}=458]$.

$$
\text { C C C C C C C C }
$$

Tables 6 and 7 about here

$$
\text { C C C C C C C }
$$

The results of Experiments 1-3 are consistent with a theory of SC structure in which an AgrP (with a phonologically null head) mediates the agreement relation between the subject of the SC and its predicate. Section 4 will consider a second series of experiments, designed to rule out Adepth of attachment@ differences as an explanation for the results reported here.

\section{EXPERIMENTS 4-6.}

As will become clear in section 5.2, it is crucial to rule out a Adepth-of-attachment@ explanation for the results of Experiments 1-3. Thus, Experiments 4-6 were designed to (i) compare the processing of structurally ambiguous sentences in Experiments 1-3 with the processing of unambiguous sentences having similar structure, and (ii) test a depth-of-attachment explanation for the results in Experiments 1-3. The experimental sentences consisted of two types of unambiguous sentences, modeled on the materials from Experiments 1-3. Using the same set of 
verbs as in Experiments 1-3, the sentences in the first condition contained an infinitival IP complement in the first region, and a predicate (Pred) conjunct in the second region (as in 23a). The sentences in the second condition contained an NP complement in the first region, and an NP conjunct in the second region (as in 23b). The category of the material at the end of the first region was distinct in each of Experiments 4 through 6 in a manner parallel with Experiments 1 through 3.

In Experiment 4 (parallel with Experiment 1), the first clause of each experimental sentence ended with an adjectival participle as in (23).

a. Mary wanted the cake to be displayed, not sitting on the cutting board on the table. (IP comp/Pred conj)

b. Mary wanted the cake which was displayed, not the one sitting on the cutting board on the table. (NP comp/NP conj) In Experiment 5 (parallel with Experiment 2), the first clause of each experimental sentence ended with a PP, as in (24).

a. Mary wanted the cake to be in the window, not sitting on the cutting board on the table. (IP comp/Pred conj)

b. Mary wanted the cake which was in the window, not the one sitting on the cutting board on the table. (NP comp/NP conj) Finally, the first clause of each experimental sentence in Experiment 6 ended with an adjective plus a PP (on a par with Experiment 3). This is shown in (25). 
a. Mary wanted the cake to be displayed in the window, not sitting on the cutting board on the table.

b. Mary wanted the cake which was displayed in the window, not the one sitting on the cutting board on the table.

In condition (a), the IP complement of wanted in region 1 is followed by a predicate conjunct in region 2. Condition (a) thereby involves the coordination of two predicates. Similarly, in condition (b), the NP complement of wanted in region 1 is followed by an NP conjunct in region 2, and condition (b) involves the coordination of two NPs. In this respect, condition (a)Cwith an IP complement and a predicate conjunctCis most parallel to the SC complement condition of Experiments 1-3, and that condition (b)Cwith an NP complement and an NP conjunctCis most parallel to the NP complement condition sentences of Experiments 1-3. The crucial difference between conditions (a) and (b) in these materials, as opposed to those of Experiments 1-3, is that the predicate at the end of region 1 in condition (a) is more deeply embedded than the NP at the end of region 1 in condition (b). This difference is illustrated in the bracketing of region 1 , shown here in (26). In each case, the string addressed by the conjunct in region 2 is underlined.

a. Mary wanted [IP the cake to [VP be [PP in the window ]]]

b. Mary wanted [NP the cake which was in the window ]

Based on these observations, we can make some predictions.

First, if the longer times found for the SC complement condition in Experiments 1-3 do correlate with depth of attachment, then we would predict longer reading times for condition (a) than for condition (b) in (23)-(25). In fact, since the predicate at the end of the first clause in (23a/24a/25a) is embedded in a VP which in turn is contained within an IP, the effects observed 
in Experiments 1-3 should be even more robust in Experiments 4-6. We can see this by comparing the contrast in depths shown above in (26) with the contrast that would be assumed under a Stowell (1981) SC-constituent analysis of SC structure.

(27) a. Mary wanted [sc the cake [PP in the window ]]] (in the SC complement condition)

b. Mary wanted [NP the cake in the window ] (in the NP complement condition)

\section{EXPERIMENT 4}

\section{METHOD}

Participants. Seventy-two undergraduates who had not participated in Experiments 1-3 participated in Experiment 4.

Materials and Design. We constructed 24 sets of sentences like those in (23). Each experimental sentence had either an IP complement in region 1 followed by a predicate conjunct in region 2, or an NP complement with a relative clause modifier in region 1 followed by an NP conjunct in region 2.

Procedure. The procedure was identical to the previous experiments.

\section{RESULTS AND DISCUSSION}

Table 8 presents mean reading times by region and condition. Table 9 presents results of the statistical analyses. We did not find in Experiment 4 that the reading times in the IP-complement/Predicate-conjunct condition (the analog of the SC condition of Experiment 1) were longer than those in the NP-complement/NP-conjunct condition (the analog of the NP complement condition); see Table 9. One-way Anovas testing reading times for the two conditions did not reveal any statistically significant differences at sitting, on, or the. At cutting, the contrast was nearly reliable by participants, but not by items. Reading times on the last word in the prepositional phrase, e.g., board, also failed to produce a statistically significant difference. 
As in the previous experiments, we performed deviation score analyses on reading times for the disambiguating regions in each condition. These analyses produced only a trend toward a reliable difference between the IP-complement/Predicate-conjunct condition (-41 ms) and the NP-complement/NP-conjunct condition $(-11 \mathrm{~ms} ; \mathrm{F} 1(1,71)=2.84, .05<\mathrm{p}<.10, \mathrm{MSe}=3061$; $\mathrm{F} 2(1,23)=3.63, .05<\mathrm{p}<.10, \mathrm{MSe}=800]$.

$$
\text { C C C C C C C C }
$$

Tables 8 and 9 about here

$$
\text { C C C C C C C C }
$$

These findings are not consistent with the hypothesis that depth-of-attachment differences caused the difference in processing difficulty between the SC and NP complement conditions in the previous three experiments. This is particularly so because the conjunct in the IP-complement/Predicate-conjunct condition is more deeply embedded, relative to the conjunct in the NP-complement/NP-conjunct condition, than was the SC conjunct in Experiment 1, relative to the NP complement conjunct [compare (26) and (27)]. Thus, the pattern of primarily unreliable differences in reading times in the IP-complement/Predicate-conjunct condition as compared with the NP-complement/NP-conjunct condition in Experiment 4 points away from depth of embedding as an explanation for the results seen in Experiment 1. In this respect, the results work against a simple constituent analysis of SC structure, and support an explanation of SC structure in which a functional Agr projection plays a crucial role.

\section{EXPERIMENT 5}

Experiment 5 evaluated processing of unambiguous materials modeled on Experiment 2.

Experiment 5 also examined whether there would be depth-of-attachment effects in processing. As was the case for Experiment 4, depth-of-attachment effects would appear as reliably longer 
reading times in the IP-complement/Predicate-conjunct condition than in the NP-complement/NP-conjunct condition, as in (24). By contrast, the Coordination Featurematching hypothesis does not predict differences based on depth of attachment. In light of the results of Experiment 4, we predicted that the results would not exhibit depth of attachment effects.

\section{METHOD}

Participants. Fifty-two undergraduates who had not participated in Experiments 1-4 participated in Experiment 5.

Materials and Design. We constructed 24 sets of sentences like those in (24). The first clause of each experimental sentence had either an IP complement or NP complement with a relative clause modifier. The predicate of the IP and the relative clause consisted of a PP. The second, conjunct, phrase consisted of the conjunction not plus either an AP or an NP conjunct. The design was as in Experiment 4.

Procedure. The procedure was identical to Experiments 1-4.

\section{RESULTS AND DISCUSSION}

Table 10 presents mean reading times by region and condition. Table 11 presents results of the statistical analyses. As in Experiment 4, Experiment 5 did not reveal reliably longer reading times in the IP-complement/Predicate-conjunct condition, the analog of the SC condition of Experiment 1, than in the NP-complement/NP-conjunct condition, the analog of the NP complement condition. One-way ANOVAs evaluating the reading time differences for the two conditions did not reveal a difference between conditions at defrosting, on, the, cutting, and board (see Table 11). Thus, depth of attachment differences across conditions cannot explain the results of Experiment 5. Instead, the data suggest that the functional Agr projection in an SC 
affected on-line sentence processing.

$$
\text { C C C C C C C C }
$$

Tables 10 and 11 about here

$\mathrm{C} \mathrm{C} \mathrm{C} \mathrm{C} \mathrm{C} \mathrm{C} \mathrm{C}$

\section{EXPERIMENT 6}

Experiment 6 tested unambiguous materials modeled on the materials from Experiment 3. If the results of Experiment 3 reflected depth-of-attachment differences across conditions, then we should also find reliably longer reading times in the critical region in Experiment 6 for the IP-complement/Predicate-conjunct condition than for the NP-complement/NP-conjunct condition. However, based on the results of Experiments 4 and 5, we instead predicted that the results in Experiment 6 would not show this difference in reading times across conditions.

\section{METHOD}

Participants. Seventy-two undergraduates who had not participated in Experiments 1-5 participated in Experiment 6.

Materials and Design. Materials were as shown above in (25). The first clause of each experimental sentence had either an IP or NP complement with a relative clause modifier. The predicate of the IP and the relative clause consisted of an adjectival participle followed by a PP. The second, conjunct, phrase consisted of the conjunction not plus either an AP or an NP conjunct. Other aspects of the design were as in Experiment 4.

Procedure. The procedure was identical to Experiments 1-5.

\section{RESULTS AND DISCUSSION}

Table 12 presents mean reading times by region and condition. Table 13 presents results of the statistical analyses.Effects similar to those observed in Experiments 4 and 5 were also 
found in Experiment 6 (see Table 13), in that reading times in the

IP-complement/Predicate-conjunct condition did not differ from reading times in the NP-complement/NP-conjunct condition. One-way ANOVAs on the reading time data did not reveal any statistically significant differences between conditions in any scoring region.

$$
\text { C C C C C C C }
$$

Tables 12 an 13 about here

$$
\text { C C C C C C C C }
$$

Depth of attachment effects were not found in Experiments 4-6, despite the fact that the structures involved would have been more likely to show a contrast than those in Experiments 13, and despite the fact that 50\% more subject were tested in Experiments 4-6 than were tested in Experiments 1-3. These results therefore support the conclusion that depth of attachment is not the factor that contributes to the longer reading times found in Experiments 1-3 for coordinated bare SC predicates. The removal of this alternative explanation, together with the results of Experiments 1-3, supports our original hypothesis, namely that processing of coordination structures is more costly when phonologically covert functional elements are present. Our initial claim, that $\varphi$-feature matching uses processing resources, is therefore supported by the results obtained across Experiments 1-6.

\section{GENERAL DisCUSSION}

In Experiments 1-3, we found that the coordination of bare SC predicates requires extra processing resources which result in longer reading times, regardless of bias. Experiments 4-6 confirmed that this processing does not correlate in any way with depth of attachment, and is not due to the mere fact of SC complements being unit constituents. Rather, our results support some recent proposals regarding SC structure, in which a SC involves an AgrP headed by a 
phonologically null functional head. A parsimonious explanation of our results is that the processing cost in the SC complement condition of Experiments 1-3 is due to the extra computations that go into determining agreement between the subject of the SC complement and the second (conjoined) SC predicate. In order to account for this, we proposed, in section 2, the Coordination Feature-Matching Principle (CFMP). This constraint works with one particular analysis of SC structure, which we have tentatively adopted. This section will first consider the question of whether CFMP provides the best explanation for what we have found. Once this is demonstrated, we will show that the CFMP clearly points to the AgrP analysis of SC structure as being the most likely (under current assumptions).

Before embarking on this discussion, a comment is in order regarding the null results observed in experiments 4-6. As noted by a reviewer of this manuscript, one must exercise utmost care in interpreting null results. Indeed it is often difficult to distinguish between a small difference and no difference. However, if depth of attachment played even a modest role in the processing of sentences such as those in experiments 4-6, then we should have observed a

difference in at least one of the three experiments. We can be very confident that the null results are not attributable to a lack of power or to a lack of sensitivity of the experimental procedure. Of course, we cannot absolutely rule out the possibility of a Type II error (i.e. missing an effect that=s actually there). However, in our view it is more likely that depth of attachment is not the relevant factor than that we were victimized by three consecutive Type II errors.

\subsection{COMPARING THE CONSTRAINTS}

Before we can be sure that that CFMP is a general principle of parsing, it is important to test this principle in other sentence constructions with properties similar to small clauses. However, the present experiments do point in this direction. This section considers several other proposed 
parsing principles, and concludes that these either make no predictions or incorrect predictions regarding the results that we observed in Experiments 1-3. We will consider, in turn, Minimal

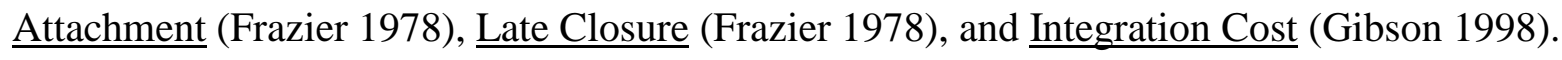

Minimal Attachment (Frazier 1978) has been applied (e.g. in Clifton et al 1991) to explain why it is that complements (i.e. arguments) of verbs and modifiers (i.e. adjuncts) of VPs are easier to process than complements of nouns and modifiers of NPs.

(28) Minimal Attachment: Do not postulate any potentially unnecessary nodes. This processing principle has little relevance to the manipulations tested in Experiments 1-3. In particular, each experimental sentence involved the addition of coordinate structure, which (presumably) involves an addition of the same number of (necessary) nodes in each instance. We conclude therefore that Minimal Attachment has little to tell us about SC structure under the conditions in which we tested it.

In contrast, Late Closure (Frazier 1978) does appear to make predictions about the conditions that we tested in Experiments 1-3, albeit wrong ones. The principle is stated in (29). (29) Late Closure: If grammatically permissible, attach new items into the clause or phrase currently being processed (i.e. the phrase postulated most recently).

A pair of example sentences which show the effects of Late Closure (taken from Frazier \& Clifton, 1996:10) is shown here in (30).

a. [s Mary kissed [NP John ... and his brother

b. [s Mary kissed [NP John and his brother] when she left]

c. [s Mary kissed John] and [s his brother started to laugh]

As (30a) shows, at the point that the sequence and his brother is encountered, both the $\mathrm{S}$ (entence) 
Mary kissed John and the NP John are being processed. The conjunction and followed by the NP

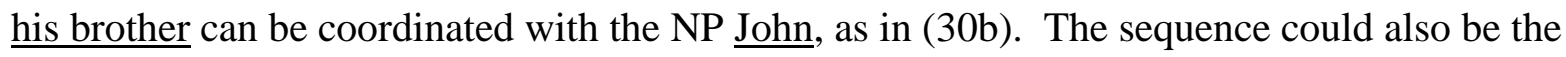
start of a new sentence, to be coordinated with Mary kissed John, as in (30c). The disambiguating words (shown in boldface) are, respectively, when and started. Frazier (1978) found that decision times (in a grammaticality judgement task) were significantly shorter for (30b) than for (30c), indicating that coordination with the NP (the lower phrase) is easier than coordination with the $\mathrm{S}$ (the higher phrase). This is predicted by Late Closure, since the NP is the most recently postulated phrase. However, if applied to the data tested in Experiments 1-3, Late Closure would appear to predict that high attachment (i.e. coordination in the NP complement condition) should result in longer reading times than lower attachment (i.e. coordination in the SC condition), which did not occur. We therefore conclude that Late Closure plays no role in the determination of reading times in the experiments reported on in this paper.

The Syntactic Prediction Locality Theory formulated in Gibson 1998 has elements that hold more promise of being applicable to the results of our experiments. However, under its current formulation, the more relevant Aintegration cost componente makes either no predictions or wrong predictions regarding our data. We will review here some aspects of this theory. The locality aspect of Aintegration cost@ suggests that Athe lexical activation of a word $\underline{w}$ decays as more words are input ...@ and that Ait takes more resources to activate the lexical head further back in the string@ (p. 11). If this principle has any relevance for the processing of coordinate structures (and it is not clear that it does), then it makes no prediction whatsoever for Experiments 1-3, since the point of disambiguation is at the same position in the string. Gibson further hypothesized that Asubstantial integration cost increments are caused by processing words 
indicating new discourse structure $($ p. 12). Under this assumption, we would anticipate elevated reading times for the integration of the one in the NP complement condition compared to sitting in the SC complement condition, since only the former involves the introduction of a new entity into the discourse. At the same time, Gibson goes on to propose that integration cost increments are also incurred Awhen intervening discourse predicates in a discourse structure ... are processed, because predicates involve additional discourse structure@ (p. 25). If this assumption is factored together with the previous one, the discourse integration cost still appears to predict the reverse of what we found. The NP complement condition involves the integration of new discourse entity the one in and a new discourse predicate sitting, while the SC complement condition only involves the integration of a new discourse predicate sitting. Our experimental results in fact confirm that discourse integrations (under Gibson=s hypotheses) play no role in the reading times that were observed, and we have to conclude that integration costs associated with discourse structure are not a factor.

This is not to say that an integration cost component is not involved, but only that the formulation of this in Syntactic Prediction Locality Theory makes the wrong predictions. In fact, one might consider the proposed CFMP as a kind of integration constraint. It differs in its application from the other sorts of integrations in that it specifically targets the grammatical integration of a specifier and its functional head. Implicit in this proposal is the notion that syntactic agreement-type integrations are of a different sort than integrations involving such things as discourse referents and anaphora. Consider the following structures.

(31) Mary wanted $[\text { the cake }]_{i}[\text { displayed }]_{i}$ not $[\text { sitting .... }]_{i}(\mathrm{SC}$ complement condition $)$

(32) Mary wanted [the $[\text { cake }]_{\mathrm{i}}$ displayed] not [the $\left.[\mathrm{one}]_{\mathrm{i}} \ldots\right] \quad$ (NP complement condition) 
In the SC complement condition, the CFMP claims that the predicate sitting (in addition to being integrated as a new discourse predicate) must have a grammatical agreement feature checked by

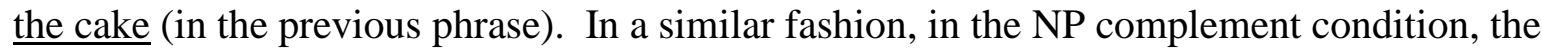
proform one in the second phrase must agree in number with its antecedent noun cake. If these processes simply involved undifferentiated Aintegration costs@ and were incurred at the same point in the processing, then we should not have had the contrast in reading times found in Experiments 1-3. If anything, the morphological salience of the anaphora in (32) might be expected to exert stronger effects than the abstract grammatical agreement in (31). We therefore conclude that the autonomous principle of syntactic processing formalized in the CFMP is needed to account for the results of these experiments.

\subsection{COMPARING THE RESULTS WITH PREVIOUS ANALYSES OF SC STRUCTURE}

Armed with what appears to be a psychologically real constraint, we can now assess the three analyses of SC structure that were presented in section 2: the SC-constituent analysis (Stowell 1981), the predication analysis (Williams 1983), and the AgrP analysis (Raposo \& Uriagereka 1990, Cardinaletti \& Guasti 1992, and Legendre 1996). We find that our results are not only consistent with the AgrP model of SC structure, but also call into question the analyses of Stowell and Williams. Williams= predication theory cannot predict the Experiment 1-3 results, and Stowell=s 1981 SC analysis can only predict them under a Adepth-of-attachment@ hypothesis, which is disconfirmed by the results of Experiments 4-6. We will examine each in turn.

Under Williams 1983a analysis, the structure of the SC interpretation of the first VP in (19) of Experiment 1 is given in (33). 


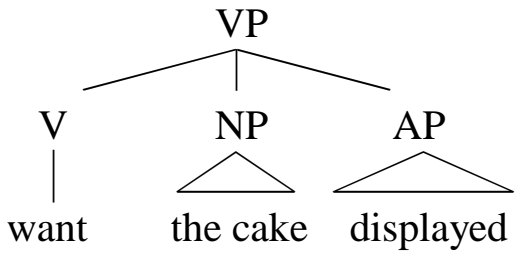

Given that this clause is biased in favor of a SC interpretation, Williams would need to assume that the processor has posited (33) as the structure for this VP, before it encounters the disambiguating conjunct. Under this theory then, the SC complement condition would present the processor with the simple task of coordinating two predicates (isplayed and sitting), while the NP complement condition would require reanalysis of (33) into (34), followed by the simple coordination of two NP complements (the cake displayed and the one sitting).

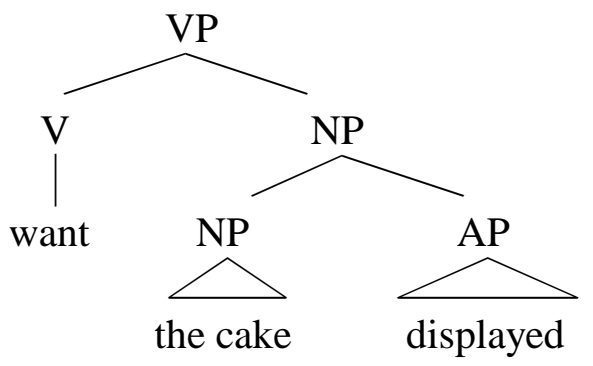

Revision is therefore the only available factor which might influence processing times under Williams = analysis. If revision occurred, we would predict the results to be the reverse of what they were in Experiment 1 (i.e. longer reading times in the NP complement condition). If revision were not a factor, it would (falsely) predict no reliable differences in reading times. Of course, Williams= analysis might correctly predict the results for Experiment 2, but only if revision from NP to SC plays a significant factor and only if the results for Experiment 1 were the reverse of what they were. William=s analysis makes no prediction in Experiment 3, where bias was not a factor.

There is thus no way, under Williams= analysis, to account for agreement as a factor in 
yielding longer reading times for coordinated SC predicates. Under his analysis, the SC predicate is a sister of its subject NP (as shown in (33)), and agreement between the subject NP and its SC predicate would have to be handled anaphorically rather than structurally. However, this leaves no way to distinguish between the SC subject-predicate agreement and the number agreement observed between the head noun and the pronominal one(s) in the NP complement condition. This contrasts with the AgrP analysis of SC structure, wherein the subject-predicate agreement in the SC is mediated by a functional projection.

If Williams= predication analysis were correct, then one would expect the association of the SC predicate with its subject antecedent to be in some measure analogous to the process that ensures number agreement between the cake $\ldots$ at the end of the first clause and the one $\ldots$ in the second conjoined phrase in the NP complement condition (compare (31) and (32), repeated here, under this approach).

(31) Mary wanted $[\text { the cake }]_{\mathrm{i}}[\text { displayed }]_{\mathrm{i}}$ not $[\text { sitting ... }]_{\mathrm{i}}(\mathrm{SC}$ complement condition $)$

(32) Mary wanted [the $[\mathrm{cake}]_{\mathrm{i}}$ displayed] not [the $\left.[\mathrm{one}]_{\mathrm{i}} \ldots\right] \quad$ (NP complement condition) Thus, under a predication analysis of SC structure, we would falsely predict the processing costs involved with the association of one with its antecedent cake in (32) to be comparable to the association of sitting with its antecedent the cake in (31). In the AgrP analysis of SC structure, $\varphi$-feature checking is a formal, structural relation mediated via Spec-head relations in the AgrP of the SC. And we might conjecture that the number agreement in the NP complement condition between the head noun and the pronominal one(s) is an anaphoric relation which does not necessarily affect on-line processing time in the same way as $\varphi$-feature checking does.

Under Stowell=s (1981) analysis, the first VP in (19) of Experiment 1 would have the 
structure given in (35).

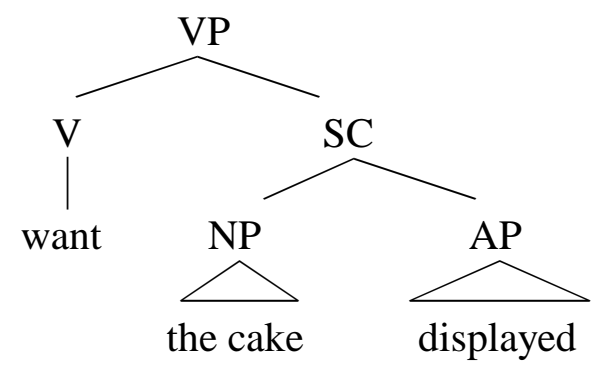

Since this clause is biased towards a SC interpretation, we can assume that for Stowell the processor will posit (35) as the structure for this VP, before it encounters the disambiguating conjunct. The SC complement condition presents the processor with the simple task of coordinating two predicates (displayed and sitting), while the NP complement condition requires reanalysis of (35) into (34), followed by the simple coordination of two NP complements (the cake displayed and the one sitting).

Stowell $=\mathrm{s}$ analysis presents one factor (besides revision) that might play a role in determining difficulty of processing under the two experimental conditions tested in Experiments 1-3. Under the SC constituent analysis, coordination in the SC condition involves conjuncts which are more deeply embedded than those in the NP complement condition. In the SC

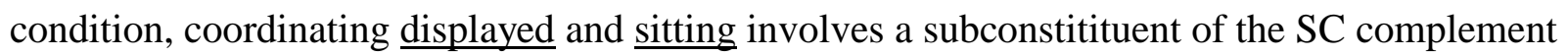
(see (35)). In the NP complement condition, the first conjunct is itself a complement of the verb want (see (34)). If depth of attachment correlates with difficulty of processing (whereby more deeply embedded conjuncts require additional processing time), then Stowell $=\mathrm{s}$ analysis could be claimed to predict the results that we found in Experiments 1-3. In section 4, however, we found through the results of Experiments 4-6, that difficulty in the SC complement condition in Experiments 1-3 cannot be attributed to depth of attachment. 
On the other hand, under the Coordination Feature-matching hypothesis, we would not have predicted reliable differences in reading times in the (a) and (b) conditions in (23)-(25). Under this hypothesis, SC predicates are assumed to involve a functional projection AgrP with a phonologically null head. Thus, the extra processing cost of checking the $\varphi$-features of the SC subject of the first clause against the Agr features in the second SC predicate conjunct should result in longer reading times. That is, the NP the cake in (36), below, must check the $\varphi$-features in the AgrP projection associated with sitting.

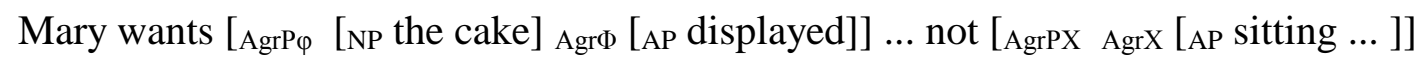

In (23a), however, there is no functional projection involved with the conjunct in the second phrase; the agreement relation between the IP subject and its predicate is mediated by the functional structure associated with the overt heads to and be. As shown in (37), (23a) involves the coordination of lexical categories only.

(37) Mary wants [IP [NP the cake] to [VP be [AP displayed]]] ... not [AP sitting ... ]

It is the presence in (36) of the AgrP (containing sitting)Cand its absence in (37)Cwhich predicts processing in (36) that is not required in (37). The fact that there were no reliable differences between conditions (a) and (b) in Experiments 4-6 appears to favor the AgrP analysis of SC structure over the SC-constituent analysis. 


\section{NOTES}

1. Although we take full credit for all of our mistakes (often), we wish to share the fact that others have helped us to take our research this far. Our thanks go out to Jesse Sears and Sachiko Matsumoto, whose lab assistance was invaluable, and for their helpful comments and suggestions to William Badecker, Samuel Bayer, William Davies, Lyn Frazier, and audiences at the LSA 1995 Annual Meeting, the 1996 CUNY Human Sentence Processing Conference, and a Johns Hopkins Cognitive Science Department Colloquium. Credit also goes to the University of South Carolina Office of Sponsored Programs and Research, which funded some of the experiments conducted in this study. The experimental materials are available from the authors upon request. 2. There is an irrelevant third interpretation for (3), in which on the table depicts the subject. In this reading Juanita considered the proposal while she was [sitting] on the table. We do not consider this interpretation in our discussion here.

3. These analyses typically assume that the head of the AP, baked, moves to $\operatorname{Agr}^{0}$ in order to have its $\varphi$-features checked.

4. We take no position here as to whether the second conjunct contains a PRO subject, or whether the structure involves coordination of non-maximal projections (i.e. projections lacking a Spec position). If PRO subjects are implicated, then we would expect that our SC results would be replicated for the coordination of resultative and depictive clauses. We leave the answer to this question for future research. 


\section{REFERENCES}

Bowers, J. (1993). The syntax of predication. Linguistic Inquiry, 24, 591-656.

Cardinaletti, A., \& Guasti, M. T. (1992). Epistemic small clauses and null subjects. Proceedings of the Eighth Eastern States Conference on Linguistics (pp. 23-33). Columbus, OH: OSU Linguistics Department.

Carrier, J., \& Randall, J. (1992). The argument structure and syntactic structure of resultatives. Linguistic Inquiry, 23, 173-234.

Chomsky, N. (1989). Some notes on the economy of derivation and representation. MIT Working Papers in Linguistics, 10. Cambridge, MA; MIT Working Papers in Linguistics.

Clifton, C., Speer, S., \& Abney, S. (1991). Parsing arguments: Phrase structure and argument structure as determinants of initial parsing decisions. Journal of Memory and Language, $\underline{30}, 251-271$.

Frazier, L. (1978). On comprehending sentences: Syntactic parsing strategies. Unpublished doctoral dissertation, University of Connecticut.

Frazier, L., \& Clifton, C. (1996). Construal. Cambridge, MA: MIT Press.

Gibson, Edward. (1998). Linguistic complexity: Locality of syntactic dependencies. Cognition $\underline{68}, 1-76$.

Hornstein, N., \& Lightfoot, D. (1987). Predication and PRO. Language, 63, 23-52.

Just, M. A., Carpenter, P. A. \& Wooley, J. D. (1982). Paradigm and processes in reading comprehension. Journal of Experimental Psychology: General, $\underline{3}$, 228-238.

Legendre, G. (1996). Secondary predication and functional projections in French. Ms., Johns Hopkins University. To appear in Natural Language and Linguistic Theory. 
Raposo, E., \& Uriagereka, J. (1990). Long-distance Case assignment. Linguistic Inquiry, 21, $505-537$.

Rizzi, L. (1986). Null objects in Italian and the theory of pro. Linguistic Inquiry, 17, 501-557.

Starke, M. (1995). On the format for small clauses. In A. Cardinaletti \& M. T. Guasti (eds.), Small clauses (pp. 237-269). Syntax and Semantics 28. New York: Academic Press.

Stowell, T. (1981). Origins of phrase structure. Unpublished doctoral dissertation, MIT.

Williams, E. (1980). Predication. Linguistic Inquiry, 11, 203-238.

Williams, E. (1983a). Against small clauses. Linguistic Inquiry, 14, 287-308.

Williams, E. (1983b). Semantic vs. syntactic categories. Linguistics and Philosophy, $\underline{6}$, 423446. 


\section{TABLES}

Table 1

Sample word-by-word moving-window display

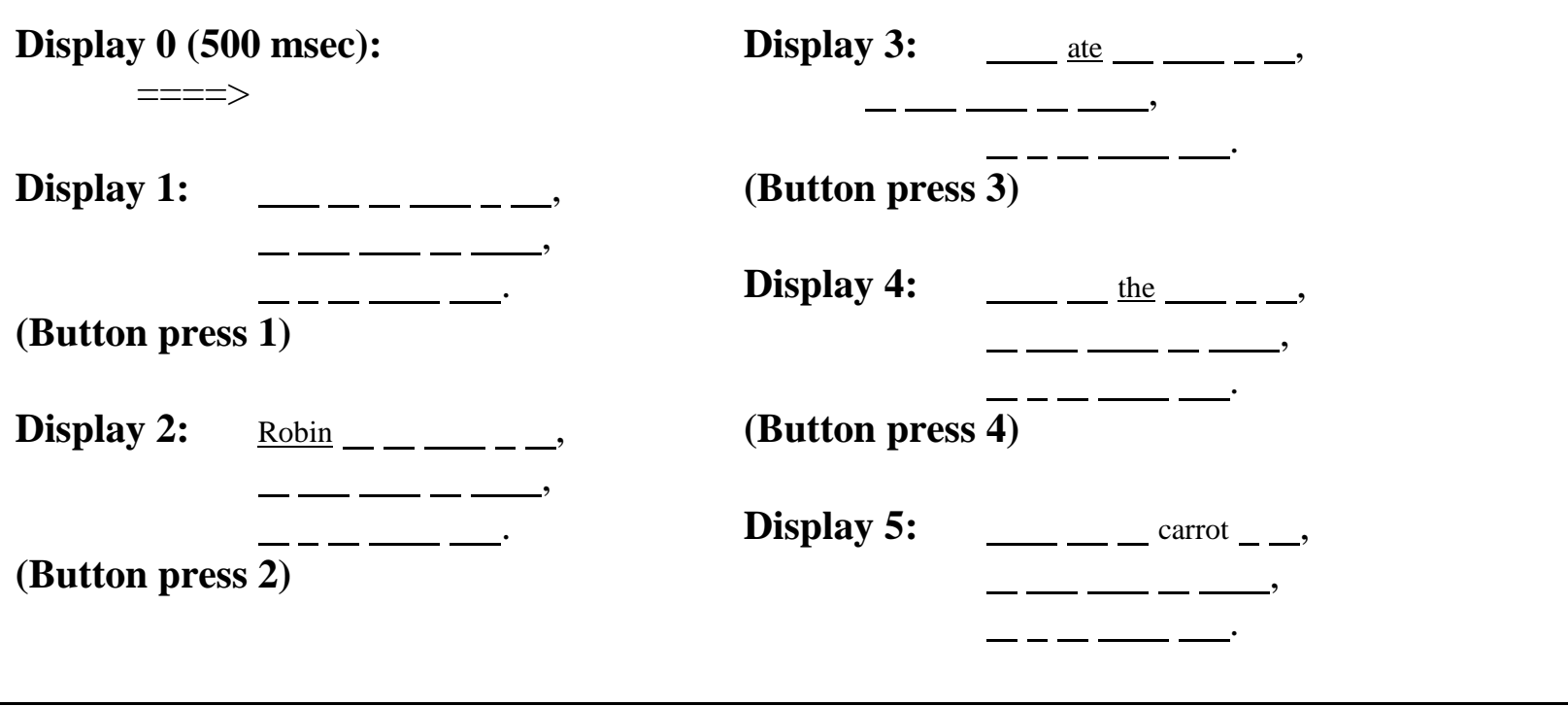


Table 2: Experiment 1 Reading Times by Region and Condition

\begin{tabular}{|c|c|c|c|c|c|c|c|c|c|c|c|c|c|c|c|}
\hline \multicolumn{16}{|c|}{ Region } \\
\hline \multirow{3}{*}{$\begin{array}{l}\text { Condition } \\
\text { SC }\end{array}$} & Mar & the & & & the & & & & & & & & & cutting & (on the \\
\hline & wan & dcake & displayed & not & one & sitting & on & the & cutti & g board & on & the & counter. & board.) & counter.) \\
\hline & 989 & 800 & 579 & 496 & -- & 416 & 409 & 372 & 384 & 415 & 390 & 380 & 518 & 1580 & 1288 \\
\hline NP & 968 & 797 & 580 & 489 & 697 & 392 & 387 & 362 & 375 & 407 & 391 & 377 & 519 & 1532 & 1287 \\
\hline
\end{tabular}


Table 3: Experiment 1 Statistical Analyses

Source: Sentence Type (SC vs. NP)
F1 (MSe)
F2 (MSe)

Region

$\begin{array}{lllll}\text { Mary wanted } & <1 & 10913 & 1.69 & 3037 \\ \text { the cake } & <1 & 3769 & <1 & 1718 \\ \text { displayed } & <1 & 2809 & <1 & 2365 \\ \text { not } & <1 & 2720 & <1 & 912 \\ \text { (the one) } & & \mathrm{NA} & & \mathrm{NA} \\ \text { sitting } & 3.97^{*} & 3318 & 5.39^{*} & 1207 \\ \text { on } & 5.81^{*} & 1981 & 5.61 * & 1040 \\ \text { the } & 1.58 & 1503 & <1 & 1107 \\ \text { cutting } & 1.03 & 1856 & 1.60 & 587 \\ \text { board } & <1 & 3338 & <1 & 1130 \\ \text { on } & <1 & 1933 & <1 & 1242 \\ \text { the } & <1 & 1247 & <1 & 1054 \\ \text { counter. } & <1 & 3604 & <1 & 1024 \\ \text { on the cutting board } & 4.37 * & 12851 & 3.53(*) 7909 \\ \text { on the counter. } & <1 & 6712 & <1 & 6327\end{array}$

Note: * indicates $\mathrm{p}<.05, * *$ indicates $\mathrm{p}<.01$, and $(*)$ indicates $.05<\mathrm{p}<.10$. Degrees of freedom are $(1,47)$ for subjects analyses and $(1,23)$ for item analyses. 
Table 4: Experiment 2 Reading Times by Region and Condition

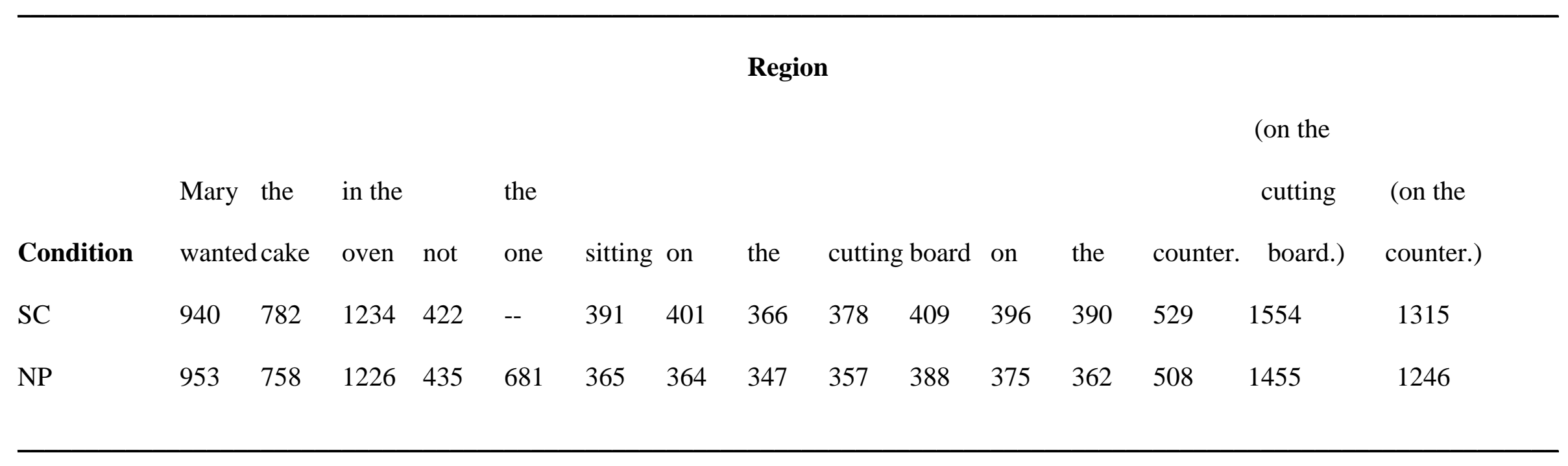


Table 5: Experiment 2 Statistical Analyses

Source: Sentence Type (SC vs. NP)

F1 $\quad$ (MSe) $\quad$ F2 $\quad($ MSe $)$

\section{Region}

$\begin{array}{lllll}\text { Mary wanted } & 1.01 & 2827 & 1.04 & 1953 \\ \text { the cake } & 4.13 * & 2330 & 9.32 * * & 729 \\ \text { in } & 2.09 & 478 & 1.46 & 490 \\ \text { the } & <1 & 961 & <1 & 333 \\ \text { window } & <1 & 1435 & <1 & 2896 \\ \text { not } & <1 & 2799 & 1.70 & 1132 \\ \text { (the one) } & \mathrm{NA} & \mathrm{NA} & \\ \text { sitting } & 7.73 * * & 1460 & 6.51 * & 1214 \\ \text { on } & 13.8 * * & 1696 & 26.2 * * & 621 \\ \text { the } & 5.29 * & 1168 & 11.2 * * & 394 \\ \text { cutting } & 8.85 * * & 854 & 8.64 * * 615 \\ \text { board } & 8.62 * * 934 & 3.57 *) & 1579 \\ \text { on } & 7.67 * * 960 & 4.48 * & 1145 \\ \text { the } & 16.0 * * & 812 & 11.8 * * & 789 \\ \text { counter. } & 4.56 * & 1607 & 1.65 & 3189 \\ \text { on the cutting board } & 25.6 * * 6501 & 23.2 & 5037 \\ \text { on the counter } & 20.2 * * 4041 & 6.28 * & 9205\end{array}$

Note: * indicates $\mathrm{p}<.05, * *$ indicates $\mathrm{p}<.01$, and $(*)$ indicates $.05<\mathrm{p}<.10$. Degrees of freedom are $(1,33)$ for subjects analyses and $(1,23)$ for item analyses. 
Table 6: Experiment 3 Reading Times by Region and Condition

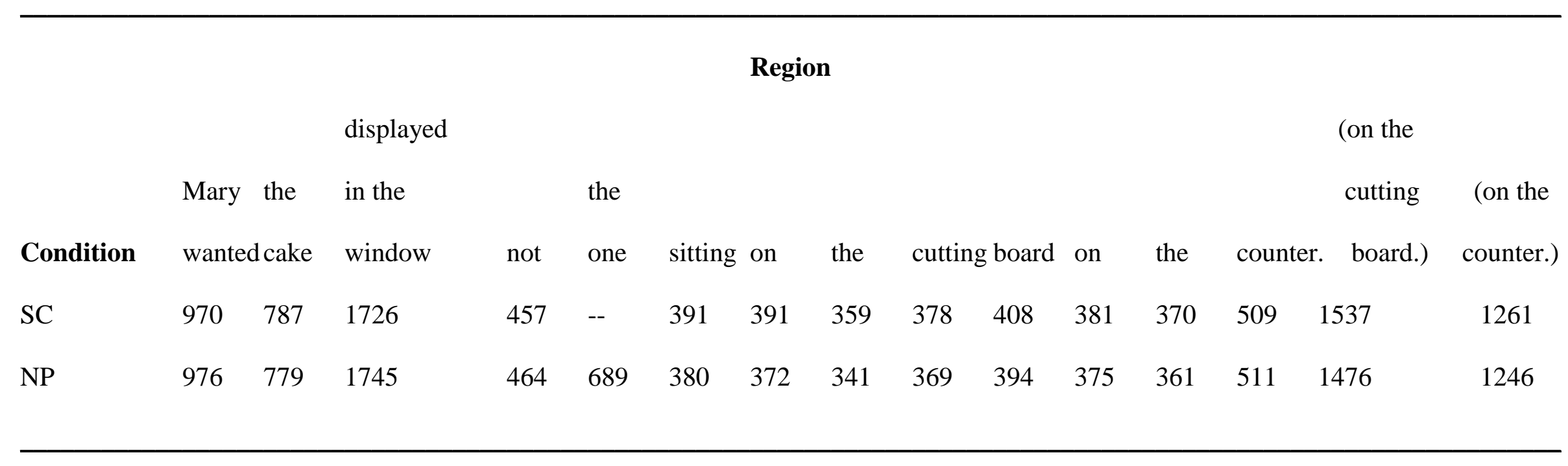


Table 7: Experiment 3 Statistical Analyses

Source: Sentence Type (SC vs. NP)
F1 (MSe)
F2 (MSe)

\section{Region}

$\begin{array}{lllll}\text { Mary wanted } & <1 & 3622 & <1 & 6198 \\ \text { the cake } & <1 & 2899 & <1 & 4209 \\ \text { displayed } & <1 & 4131 & <1 & 1183 \\ \text { in } & <1 & 1482 & <1 & 758 \\ \text { the } & <1 & 1193 & <1 & 608 \\ \text { window } & 1.89 & 3253 & 2.24 & 1460 \\ \text { not } & <1 & 1110 & <1 & 1015 \\ \text { (the one) } & \mathrm{NA} & & \mathrm{NA} & \\ \text { sitting } & 2.16 & 1283 & 1.47 & 977 \\ \text { on } & 5.75^{*} & 1479 & 4.88^{*} & 857 \\ \text { the } & 8.16^{* *} & 1020 & \left.3.033^{*}\right) 1394 \\ \text { cutting } & 1.47 & 1393 & <1 & 1116 \\ \text { board } & 4.04 * & 1164 & 3.28(*) 727 \\ \text { on } & <1 & 1230 & <1 & 837 \\ \text { the } & 1.34 & 1605 & 1.08 & 998 \\ \text { counter. } & <1 & 2466 & <1 & 820 \\ \text { on the cutting board } & 9.37 * * 9437 & 4.43^{*} & 9847 \\ \text { on the counter } & <1 & 9269 & <1 & 3980\end{array}$

Note: $*$ indicates $\mathrm{p}<.05, * *$ indicates $\mathrm{p}<.01$, and $(*)$ indicates $.05<\mathrm{p}<.10$. Degrees of freedom are $(1,47)$ for subjects analyses and $(1,23)$ for item analyses. 
Table 8: Experiment 4 Reading Times by Region and Condition

\begin{tabular}{|c|c|c|c|c|c|c|c|c|c|c|c|c|c|c|c|c|}
\hline \multirow[b]{3}{*}{ Condition } & \multirow{3}{*}{\multicolumn{2}{|c|}{$\begin{array}{l}\text { Mary the } \\
\text { wanted cake }\end{array}$}} & \multirow{2}{*}{\multicolumn{2}{|c|}{ to be/ }} & \multicolumn{7}{|c|}{ Region } & \multicolumn{4}{|c|}{ (on the } & \multirow{2}{*}{$\begin{array}{l}\text { (on } \\
\text { the }\end{array}$} \\
\hline & & & & & & & the & & & & & & & & cutting & \\
\hline & & & which & was & displaye & not & one & sitting & on & the & cutting & board & on the & counter. & board) & counter.) \\
\hline $\mathrm{SC}$ & 1012 & 816 & 764 & 764 & 541 & 487 & -- & 413 & 381 & 354 & 391 & 422 & 398377 & 523 & 1547 & 1297 \\
\hline NP & 1018 & 808 & 779 & 779 & 544 & 486 & 699 & 404 & 382 & 349 & 373 & 405 & 398371 & 1506 & 1297 & 1276 \\
\hline
\end{tabular}


Table 9: Experiment 4 Statistical Analyses

Source: Sentence Type (SC vs. NP)
F1 (MSe)
F2 (MSe)

\section{Region}

$\begin{array}{lllll}\text { Mary wanted } & <1 & 14386 & <1 & 8185 \\ \text { the cake } & <1 & 5933 & <1 & 8146 \\ \text { to be/which was } & 1.58 & 5004 & <1 & 6659 \\ \text { displayed } & <1 & 4088 & <1 & 5414 \\ \text { not } & <1 & 5765 & <1 & 2431 \\ \text { (the one) } & \mathrm{NA} & & \mathrm{NA} & \\ \text { sitting } & <1 & 3428 & <1 & 2321 \\ \text { on } & <1 & 2899 & <1 & 1395 \\ \text { the } & <1 & 1268 & <1 & 1784 \\ \text { cutting } & 3.86 * & 3110 & 1.54 & 2576 \\ \text { board } & 2.24 & 4156 & 1.18 & 2647 \\ \text { on } & <1 & 2981 & <1 & 2014 \\ \text { the } & <1 & 1385 & <1 & 1649 \\ \text { counter. } & 2.11 & 4560 & \mathbf{? ?} & ? ? \\ \text { on the cutting board } & 2.78 & 18673 & <1 & 21684 \\ \text { on the counter } & 1.63 & 10413 & <1 & 16362\end{array}$

Note: $*$ indicates $\mathrm{p}<.05, * *$ indicates $\mathrm{p}<.01$, and $(*)$ indicates $.05<\underline{\mathrm{p}}<.10$. Degrees of freedom are $(1,71)$ for subjects analyses and $(1,23)$ for item analyses. 
Table 10: Experiment 5 Reading Times by Region and Condition

\begin{tabular}{|c|c|c|c|c|c|c|c|c|c|c|c|c|c|c|}
\hline & & & & & & & Region & & & & & & (on the & (on \\
\hline & Mary & the & to be/ & in the & & the & & & & & & & cutting & the \\
\hline Condition & wante & d cake & which was & window & not & one & sitting on & the & cuttin & gboard & on the & counter. & board) & counter.) \\
\hline $\mathrm{SC}$ & 1116 & 944 & 982 & 1400 & 484 & -- & 464 & 417 & 459 & 473 & 452455 & 596 & 1791 & 1504 \\
\hline NP & 1120 & 949 & 897 & 1440 & 496 & 838 & 439 & 414 & 452 & 467 & $451 \quad 437$ & 569 & 1772 & 1457 \\
\hline
\end{tabular}




\section{Table 11: Experiment 5 Statistical Analyses}

Source: Sentence Type (SC vs. NP)

F1 (MSe) F2 (MSe)

\section{Region}

$\begin{array}{lllll}\text { Mary wanted } & <1 & 13031 & <1 & 5824 \\ \text { the cake } & <1 & 6386 & <1 & 2886 \\ \text { to be/which was } & <1 & 8552 & <1 & 3878 \\ \text { in the window } & 4.51^{*} & 9382 & 3.06\left(^{*}\right) 2162 \\ \text { not } & 1.70 & 2095 & <1 & 1672 \\ \text { (the one) } & \mathrm{NA} & & \mathrm{NA} & \\ \text { sitting } & 1.46 & 4769 & <1 & 2287 \\ \text { on } & <1 & 2683 & <1 & 1171 \\ \text { the } & <1 & 1448 & <1 & 1788 \\ \text { cutting } & <1 & 5712 & <1 & 1885 \\ \text { board } & <1 & 2918 & <1 & 2056 \\ \text { on } & <1 & 2860 & <1 & 676 \\ \text { the } & 4.52^{*} & 1879 & 3.76(*) 1020 \\ \text { counter. } & 4.01^{*} & 4817 & ? ? & \\ \text { on the cutting board } & <1 & 15746 & <1 & 11126 \\ \text { on the counter } & 4.87^{*} & 11745 & 3.34(*) 7862\end{array}$

Note: * indicates $\mathrm{p}<.05, * *$ indicates $\mathrm{p}<.01$, and $(*)$ indicates $.05<\underline{\mathrm{p}}<.10$. Degrees of freedom are $(1,51)$ for subjects analyses and $(1,23)$ for item analyses. 
Table 12: Experiment 6 Reading Times by Region and Condition

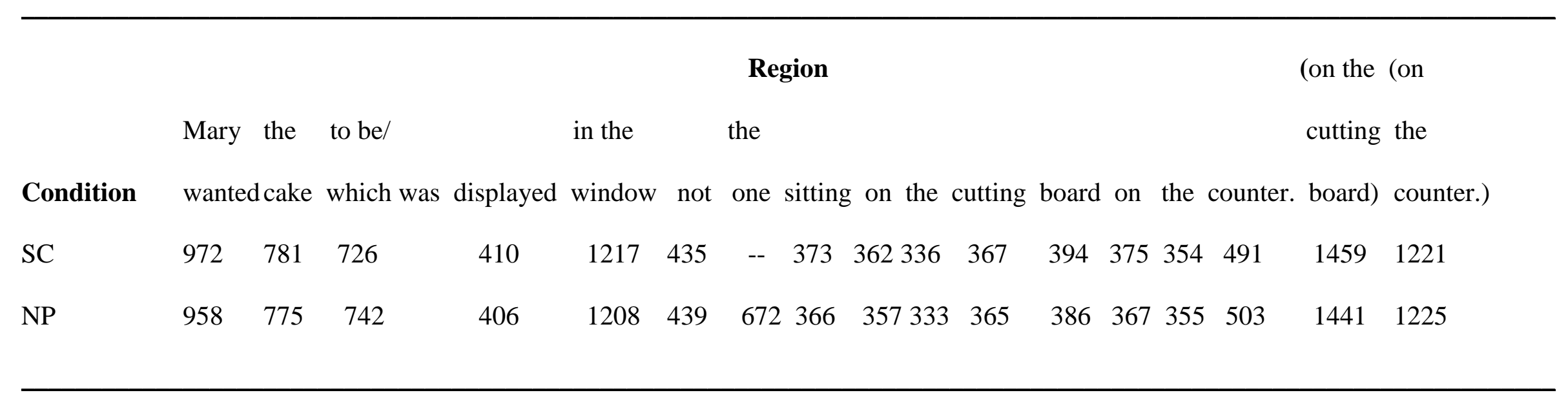




\section{Table 13: Experiment 6 Statistical Analyses}

Source: Sentence Type (SC vs. NP)

F1 (MSe) F2 (MSe)

\section{Region}

$\begin{array}{lllll}\text { Mary wanted } & <1 & 11708 & 1.15 & 2008 \\ \text { the cake } & <1 & 6062 & <1 & 3825 \\ \text { to be/which was } & 2.64 & 3370 & 1.49 & 2040 \\ \text { displayed } & <1 & 2719 & <1 & 2123 \\ \text { in the window } & <1 & 8467 & <1 & 5405 \\ \text { not } & <1 & 2993 & <1 & 1001 \\ \text { the one) } & \mathrm{NA} & & \mathrm{NA} & \\ \text { sitting } & 1.08 & 2046 & <1 & 1374 \\ \text { on } & <1 & 1416 & <1 & 565 \\ \text { the } & <1 & 1319 & <1 & 307 \\ \text { cutting } & <1 & 2090 & <1 & 1606 \\ \text { board } & <1 & 2892 & <1 & 1399 \\ \text { on } & 1.77 & 1617 & 1.07 & 888 \\ \text { the } & <1 & 1269 & <1 & 600 \\ \text { counter. } & 1.92 & 2580 & ? ? & ? ? \\ \text { on the cutting board } & <1 & 12773 & <1 & 8096 \\ \text { on the counter } & <1 & 9074 & <1 & 8388\end{array}$

Note: $*$ indicates $\mathrm{p}<.05, * *$ indicates $\mathrm{p}<.01$, and $(*)$ indicates $.05<\mathrm{p}<.10$. Degrees of freedom are $(1,71)$ for subjects analyses and $(1,23)$ for item analyses. 